\title{
Multiscale molecular dynamics-FE modeling of polymeric nanocomposites reinforced with carbon nanotubes and graphene
}

\author{
Doagou-Rad, S.; Jensen, J. S.; Islam, A.; Mishnaevsky Jr., Leon
}

\section{Published in:}

Composite Structures

Link to article, DOI:

10.1016/j.compstruct.2019.03.017

Publication date:

2019

Document Version

Peer reviewed version

Link back to DTU Orbit

Citation (APA):

Doagou-Rad, S., Jensen, J. S., Islam, A., \& Mishnaevsky Jr., L. (2019). Multiscale molecular dynamics-FE modeling of polymeric nanocomposites reinforced with carbon nanotubes and graphene. Composite Structures, 217, 27-36 . https://doi.org/10.1016/j.compstruct.2019.03.017

\section{General rights}

Copyright and moral rights for the publications made accessible in the public portal are retained by the authors and/or other copyright owners and it is a condition of accessing publications that users recognise and abide by the legal requirements associated with these rights.

- Users may download and print one copy of any publication from the public portal for the purpose of private study or research.

- You may not further distribute the material or use it for any profit-making activity or commercial gain

- You may freely distribute the URL identifying the publication in the public portal 


\section{Accepted Manuscript}

Multiscale molecular dynamics-FE modeling of polymeric nanocomposites reinforced with carbon nanotubes and graphene

S. Doagou-Rad, J.S. Jensen, A. Islam, Leon Mishnaevsky Jr.

PII:

S0263-8223(18)31057-2

DOI: https://doi.org/10.1016/j.compstruct.2019.03.017

Reference: COST 10745

To appear in:

\section{Composite Structures}

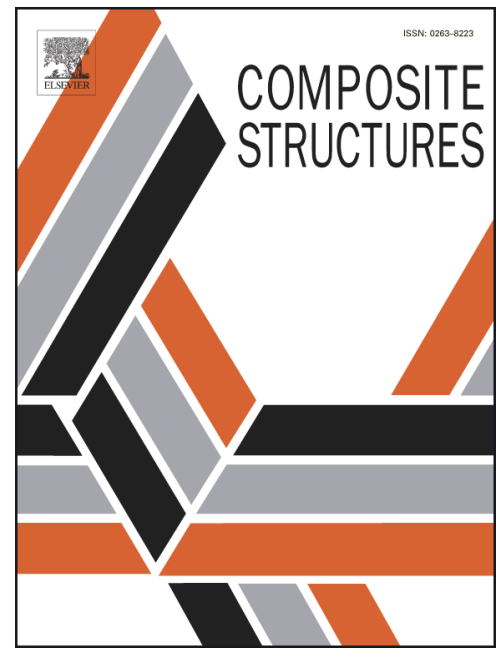

Received Date: 19 March 2018

Revised Date: $\quad 25$ February 2019

Accepted Date: $\quad 1$ March 2019

Please cite this article as: Doagou-Rad, S., Jensen, J.S., Islam, A., Mishnaevsky, L. Jr., Multiscale molecular dynamics-FE modeling of polymeric nanocomposites reinforced with carbon nanotubes and graphene, Composite Structures (2019), doi: https://doi.org/10.1016/j.compstruct.2019.03.017

This is a PDF file of an unedited manuscript that has been accepted for publication. As a service to our customers we are providing this early version of the manuscript. The manuscript will undergo copyediting, typesetting, and review of the resulting proof before it is published in its final form. Please note that during the production process errors may be discovered which could affect the content, and all legal disclaimers that apply to the journal pertain. 


\title{
Multiscale molecular dynamics-FE modeling of polymeric nanocomposites reinforced with carbon
} nanotubes and graphene

\author{
S. Doagou-Rad ${ }^{\mathrm{a}, \mathrm{b}, *}$, J. S. Jensen $^{\mathrm{a}}$, A. Islam $^{\mathrm{a}, \mathrm{b}}$, Leon Mishnaevsky Jr. ${ }^{\mathrm{c}}$ \\ ${ }^{\text {a }}$ Centre for Acoustic Mechanical Microsystems (CAMM), Technical University of Denmark, Building 352 , \\ DK-2800 Kgs. Lyngby, Denmark \\ ${ }^{\mathrm{b}}$ Department of Mechanical Engineering, Technical University of Denmark, Produktionstorvet, Building \\ 427A, DK-2800 Kgs. Lyngby, Denmark \\ ${ }^{\mathrm{c}}$ Department of Wind Energy, Ris $\varnothing$ Campus, Technical University of Denmark Frederiksborgvej 399, 4000 \\ Roskilde, Denmark \\ * Corresponding author. Tel.: +45-4525-4867; fax: +45-4525-4700. E-mail address: sadora@ mek.dtu.dk
}

\begin{abstract}
A multiscale model to investigate the influence of content and morphology on the elastic properties of composites reinforced with carbonic nanofillers is developed. The modeling consists of two consecutive steps of initial molecular dynamics followed by finite element or micro mechanical modeling. The stiffness matrices of Carbon NanoTubes and Graphene NanoPlatelets are fully characterized through molecular dynamics simulations. The results show that exceeding a certain diameter or number of layers, nearly constant values can be considered for the stiffness parameters of nanofillers. Subsequently, realistic morphology based microstructures inspired from conducted electron microscopy studies on the produced composites are analyzed using the finite element method. The results show that simultaneous application of accurate nanofiller properties and realistic composite morphologies can capture the experimental values effectively. In fact, both simulations and experiments show that a fully curved random configuration of the carbon nanotubes leads to decreased rates of enhancement for higher filler content, which proves that the reduction of enhancement rate is not just a collateral influence of agglomerations in the nanocomposite structures. Comparison of computational and Mori-Tanaka modeling with experimental results has also revealed their potential and limitation in predicting the nano and hybrid composites behaviors.
\end{abstract}


Keywords: Polymer-matrix composites ; Finite element analysis; Molecular dynamics; Micro-mechanics;

Mechanical testing

\section{Introduction}

The advent of nano materials in the last decades promoted significant interest for many different applications. The extraordinary properties of novel materials such as Carbon nanotubes (CNTs), Graphene NanoPlatelets (GNPs), nanodiamonds, nanoclays, etc. excited scientific and industrial communities. It was expected that their inclusion within a polymeric matrix would result in exceptional lightweight composites with highly enhanced properties. However, after significant number of publications, their processing, manufacturing, and modeling are still challenging, and often do not meet initial expectations [1,2]. In order to predict the properties, researchers initially tried to apply traditional composite models such as Halpin-Tsai, Mori-Tanaka, Hashin, Cox shear-lag, etc. [3-7]. However, these models were developed for the composites reinforced with larger fillers. The experimental results soon showed that the application of available analytical models could not predict the observed experimental behavior in the new composites [6,8,9]. A number of correction coefficients were proposed to compensate for the observed differences between the conventional analytical models and experimental outcomes [6]. Many of these modifications were constructed based on available experimental values in the literature. However, the experimental results comprised a wide range of variation from significant enhancements to even negative impacts [9]. In fact, based on the type of nanofiller, processing method, and matrix characteristics, the experimental results could vary drastically.

Another source of deviation arose from the fact that experimental characterization of nanofillers has been quite challenging and expensive [10,11]. Due to a wide range of characteristics such as aspect ratio, size, defects etc., variable experimental results have been reported. Therefore, inconsistent values for the same property of a type of nanofiller can be often noticed in the literature. For instance, a range of 0.3-4.0 TPa has been used as the longitudinal elastic modulus of carbon nanotubes. By improvements in the computational power, simulation methods such as molecular dynamics (MD) and molecular mechanics (MM) became viable alternatives to the nanoscale experiments. Application of molecular dynamics simulations provided a better understanding of the influential mechanisms within the nanostructured composites [12,13]. Moreover, many characterizations at the nanoscale not possible using experiments became feasible. However, molecular 
dynamics simulations are limited to a few micrometers in size, and up to microseconds in the time span of simulations.

On the other hand, finite element (FE) modeling as a more versatile tool has been used to predict the properties. FE models could include many of the elements missing in the analytical models [4,14-22]. However, many of the constructed models were quite simplistic compared to the complexity of the structure in the nanocomposites. Therefore, many of the performed simulations missed the involved phenomena acting in the structure of the nanocomposites. In fact, while the nanocomposite properties are critically dependent on the morphology of the microstructure of the materials, some influential parameters such as geometry, arrangement and interactions have usually been idealized.

The purpose of this study is to implement a more realistic multiscale modeling of the nanocomposites to study their elastic behavior. Investigation of the influence of morphology and nanofillers content on the elastic behavior of the nanocomposites using the three different methods including the devised multiscale approach, analytical micromechanical modeling, and experiments are targeted. Composites containing single or combinations of carbonic nanofillers (carbon nanotubes and graphene nanoplatelets) are considered. In order to compare results from the different sources, characteristics of the modeling constituents are acquired from the statistical electron microscopy investigations. The acquired properties of the nanofillers are included in the performed molecular dynamics simulations. The conducted MD experiments lead to acquisition of the stiffness matrix of the nanofillers. Subsequently, the achieved stiffness matrices of the nanofillers are incorporated into micromechanical and finite element models. Representative volume elements (RVEs) of nano and hybrid composites with different morphologies mimicked from the microstructure of the produced samples are constructed using FE models. The FEM results are finally compared with Mori-Tanaka micromechanical modeling and experimental results to evaluate their effectiveness.

\section{Experimental methods}

The MWCNTs used in this study are catalytic chemical vapor deposition produced thin MWCNTs (NC $7000^{\mathrm{TM}}$ ) by Nanocyl SA, Belgium, and the Graphene NanoPlatelets were acquired from XGSciences, USA. Both nanofillers are commercially available, and are viable for industrial applications. A Polyamide or Nylon 
(PA 6,6) from ALBIS Plastic GmbH, Germany (Altech PA6,6, $\mathrm{Tg}=54.8^{\circ} \mathrm{C}, \mathrm{Tm}=262.9^{\circ} \mathrm{C}$ ) was used as the matrix $[2,23]$.

A conical counter rotating twin-screw extruder $\left(\mathrm{HAAKE}^{\mathrm{TM}}\right.$ Rheomex CTW) was selected to perform the melt mixing process. PA 6,6 based masterbatches filled with 15.0 wt. \% of the aforementioned MWCNTs, and 12.0 wt. \% of the GNPs were prepared initially to be used in the dilution process. Prior to feeding the materials to the extruder, the neat polymer and masterbatches were dried, weighted, and hand-mixed in sealed bags. During the blending process in the twin screw extruder, the temperature distribution was kept from 265 to $280 \mathrm{oC}$ (feed section to die), with the average temperature of $275{ }^{\circ} \mathrm{C}$ and the melting screw speed was 25 $\operatorname{rpm}[2,23,24]$. Two series of PA 6,6 based nanocomposites with the different contents of 0.5, 1.0, 3.0, and 5.0 wt. \% of MWCNTs and GNPs were produced. In addition, hybrid nanocomposites comprising different ratios of MWCNTs and Graphene NanoPlatelets were produced. The ratios of MWCNTs to GNPs within the polymeric composition of the hybrid nanocomposites were $1.0 / 2.0$ and $2.0 / 1.0 \mathrm{wt}$. \%. It is also noteworthy to mention that in this paper the contents of the nanofillers in all sections are presented in weight percentages to make the results comparable. Subsequently, injection molding of the nanocomposite specimens was performed on a Ferromatik, Milacron, USA following the instructions of ISO 294-1. The geometry of the cavity of the mold was dog-bone shape which was designed based on ISO 527-2 2012.

Uniaxial tensile characterization of the injection-molded dog-bone shape specimens were conducted using a MTS 858, USA according to ISO 527-1 2012 in order to acquire the elastic modulus of the specimens. From each series of specimens produced via the defined setting and content, 10 samples were selected randomly, and tested in the dry as molded state. In order to study the distribution and dispersion of nanofillers, scanning electron microscopy (SEM) (Quanta FEG 200 ESEM) was employed on the fractured surfaces of the nanocomposites. In addition, transmission electron microscopy (TEM) (FEI Tecnai ${ }^{\mathrm{TM}} \mathrm{G}^{2} 20$ ) was used on the ultramicrotomed (Leica Ultracut UCT, Leica Microsystems, Germany) films with $70 \mathrm{~nm}$ thickness in order to study the orientation and arrangement of the nanofillers within the polymeric system.

\section{Computational methods}

\subsection{Molecular dynamics}

Molecular dynamics simulations were conducted to determine the stiffness matrix elements of carbon 
nanotubes and graphene nanoplatelets at atomistic scales. MD simulations offer an appropriate and effective means to deal with large systems and relatively longer simulation times. All MD simulations were conducted using large-scale atomic/molecular massively parallel simulator (LAMMPS) [25]. For the short-range bonding atomistic interactions within each layer of the Multi-Walled Carbon NanoTubes (MWCNTs) or graphene sheets, Adaptive Inter-molecular Reactive Empirical Bond Order (AIREBO) potential, which is a multi-body force field developed for hydro-carbons was considered [26]. The AIREBO potential includes the second generation REBO potential EREBO [27], the torsion potential $\left(E^{\text {TORSION }}\right)$, and the Lennard Jones potential $\left(E^{L J}\right)$. The second generation REBO potential $E^{R E B O}$ controls the covalent bond interactions. In addition, $E^{\text {TORSION }}$ and $E^{L J}$ control dihedral rotation of bonds, and long range non-bonded interactions between the atoms within each single layer, respectively.

Atomistic simulations were conducted on single and multi-layered/walled carbon nanotubes and graphene nanoplatelets comprising 1 to 12 number of layers (See Fig. 1). All studied calculations were performed on nanotubes and graphene nanofillers enclosed in cubic cells. Periodic boundary conditions were imposed on the three directions of the simulation boxes. The simulated graphene sheets were $15 \times 15 \mathrm{~nm}^{2}$ ( 9000 atoms), and carbon nanotube lengths were $20 \mathrm{~nm}(24600$ atoms for chirality $(75,75))$. Static and dynamic calculations were performed on environmental temperatures of $0.001 \mathrm{~K}$ and $300 \mathrm{~K} .0 .3 \%$ strain with a strain increment of $1 \times 10^{-5}$ were imposed on the simulations boxes. A conjugate gradient algorithm was used to minimize the total potential energy of the system with respect to the normal direction to the applied strain. Stiffness characteristics of the transversely nanofillers at zero temperature were attained using an atomic relaxed method, which is based on the determination of the elastic energy as the function of the applied strain [26]. Using this molecular mechanics method, the total potential energy of the system is minimized before and after each applied strain step. After each strain increment following the minimization, the stress tensors and potential energies are calculated and recorded. Therefore, the stress values as the function of the imposed strains are attained. In all of the simulations, a convergence criterion of $1 \times 10^{-20}$ ev were used for the conjugate gradient energy minimizations. A Nose-Hoover thermostat was also used to adjust the environmental temperatures in order to avoid any undesirable thermal impacts [28]. In order to attain the initial configuration for the dynamic simulations, nanofillers are equilibrated to release any residual stresses. 
Nanofillers were simulated under NVT ensemble for $300 \mathrm{ps}$ to equilibrate. The equations of motion in all MD simulations were integrated using Velocity Verlet algorithm with an integration time step of $1 \mathrm{fs}$. Since the elastic behavior was targeted and the results of the dynamic and static simulations were quite similar $(<5 \%$ deviation in $0.3 \%$ strain) the perfectly elastic results obtained from the simulations at $0.001 \mathrm{~K}$ are reported. Moreover, the stiffness values at $0.001 \mathrm{~K}$ do not depend on the size of the nanofillers. According to the loading scenario, the value of the targeted stiffness element entries in the system (five independent elements in the transversely isotropic stiffness matrix) are calculated as:

$$
C_{i j m n}=\frac{1}{V} \frac{\partial^{2} U}{\partial \varepsilon_{m n} \partial \varepsilon_{i j}}
$$

where $U$ is the potential energy in the system, and $\varepsilon$ is the imposed strain on the nanofillers. Thickness of a single nanotube or graphene layer has been considered as $0.34 \mathrm{~nm}$.

Fig. 1

\subsection{Finite element modeling}

Constructing Representative Volume Elements (RVEs) of the composite systems using the finite element method is a powerful tool to simulate their behavior. This approach provides the versatility to implement complex morphologies and microstructures of different composites systematically. In order to conduct computational experiments on the nanofillers reinforced polymers, a series of 3D computational models were constructed. The desired microstructures were generated into RVEs using a developed Python based software code described in [29-33]. In order to implement realistic nanofiller features in the computational models, a chain system of models were used. In fact, the prepared Fortran code uses stiffness matrixes of matrix and reinforcements, type, volume content, and arrangement and geometrical aspects of the nanofillers as the input parameters. The resulting Python codes are used as the input in the finite element software to build the different FE models with the defined parameters. The implemented chain system would also make sure that the nanofillers are not intersecting and the physical features are viable. In order to construct nanotubes in the models, the coordinates of initial point of each nanofiber was defined by three random numbers inside the cell. Subsequently, the next point is determined by defining two random angles ( 0 to 360 degrees). The 
following turning point is defined by new random angles (-60 to 60 degrees). Following the generation of the points, wires were constructed through the points. Round sections of the given diameter were swept through the array of points to create each nanofiber. Similar to nanotubes, GNPs were constructed by initial definition of a random number as the center of the plane circles and transforming them into discs by adding the defined thickness. Subsequently, a random vector ( 0 to the length of RVE) translate them into the RVE box and additional random axis direction and angle (0 to 180 degrees) are assigned to rotate them. In order to add subsequent nanofillers inside the unit cell, the Random Sequential Adsorption approach (RSA) was incorporated in the program [33]. RSA approach for the snake-shaped inclusions consists of sequential addition of randomly oriented reinforcements to a unit cell to guarantee that the nanofillers do not overlap. The distances between newly generated points and all the available points were checked at each step. If the points were located at the same coordinates, too close or out of box, the point was re-generated by the RSA algorithm. Further, if the line segments coincide, the second point of a new line segment was generated again. In order to mesh the acquired complex geometries, two options were included in the developed program: geometry based meshing, and embedding element meshing. The first option works well when the number of kinks and the nanofillers aspect ratio are limited. However, for more complex structures (large aspect ratio, and with many kinks), the structures with very fine meshes are embedded into regular meshes of the unit cell.

Three categories of 3D FE models including different contents of CNTs, GNPs, and different combinations of CNTs/GNPs were constructed. The used nanofillers' geometries and morphologies were acquired from the TEM and SEM micrographs of thin cross section of the produced composites. In fact, the observed morphologies in the produced specimens inspired the construction of RVE models. A random homogenized composite structure model including sufficient number of the nanofillers represents morphologies independent from randomness within the RVE. In other words, different random arrangements of the same nanofillers content within the RVE lead to similar homogenous and isotropic behavior. Therefore, the homogenized random RVEs can be considered as viable representative of the real produced specimens. The features such as snake-like positioning of the nanotubes, entanglement of the nanofillers, and the number of agglomerates were considered in such approach. Different morphologies including random or aligned 
arrangement of the nano inclusions were modeled to study the influence of morphology on the mechanical performance of the composites.

The simulations are conducted using the commercial FE code ABAQUS implicit. Quadratic tetrahedral elements (C3D10) were used to mesh the FE models. Sensitivity analyses showed that based on the included morphology and content, 1 or $2 \mu \mathrm{m}$ cell lengths lead to stable homogenized results. Elastic moduli in the three directions were attained by applying a $0.3 \%$ uniform strain on the corresponding surface. The reaction force on the opposite surface was calculated to obtain the stress in the RVE. The normal directions at the rest of surfaces were kept fixed. It is also noteworthy to mention that in order to implement the anisotropy of the nanofillers in the models, separate coordinate systems were defined for each inclusion. In other words, as the orientation of the nanotubes varies following the defined spines, the stiffness matrix is defined on every element on the cross section of the tube. Therefore, as the stiffness matrixes vary on the global coordinates, the stiffness matrixes in each local coordinate are the derived elements from the MD simulation regardless of orientation or curvature of the fillers [34]. This topology based orientation allows a right-handed Cartesian coordinate system be defined continually through the varying orientation. ABAQUS uses these defined normal and primary axes to construct the varying coordinate systems (See Fig. 2).

Fig. 2

Acquiring least standard deviation of the elastic moduli in the three directions of the random structures were considered as the determinant parameter in finding the required number of nanofillers and the length of unit cell. Mesh-seed lengths of $10 \mathrm{~nm}$ were also used, which lead to $600 \mathrm{k}$ to 1 million elements in the models depending on the size and content. Fig. 3 presents the six major types of the built RVEs.

Fig. 3

\subsection{Analytical micromechanical modeling}

The acquired transversely isotropic stiffness matrixes of the nanofillers from MD simulations along with the isotropic elastic properties of the neat polymer (PA 66) were used as input to the micromechanical models to estimate the elastic moduli of the nanocomposites. The micromechanical models represent the homogenized composite elastic properties including different arrangements of the nanofillers. Using the equivalent continuum model based on the Eshelby-Mori-Tanaka approach enables us to attain the 
homogenized stiffness matrix of the nanocomposites [35,36]. The effective stiffness tensor $[C]$ of the twophase nanocomposites can be estimated as [37]:

$$
C=C_{m}+c_{r}\left\langle\left(C_{r}-C_{m}\right) A_{r}\right\rangle\left(\left(1-c_{r}\right) I+c_{r}\left\langle A_{r}\right\rangle\right)^{-1}
$$

where $C, C_{m}$, and $C_{r}$ are nanocomposite, matrix, and reinforcement stiffness tensors, respectively. In addition, $c_{r}$ is the reinforcement volume fraction, and $I$ is the identity tensor. $A_{r}$ represents the dilute mechanical strain concentration tensor:

$$
A_{r}=\left[I+S\left(C_{m}\right)^{-1}\left(C_{r}-C_{m}\right)\right]^{-1}
$$

where $S$ is Eshelby tensor. Considering long cylindrical inclusions as CNTs, and thin penny shapes as GNPs, Eshelby tensor elements can be estimated from the Mura's theory [38]:

\begin{tabular}{l|c|c} 
& $\mathrm{CNT}$ & \multicolumn{1}{c}{ Graphene } \\
\hline Eshelby & $S_{2222}=S_{3333}=\frac{5-4 v_{m}}{8\left(1-v_{m}\right)}, S_{2233}=S_{3322} \frac{4 v_{m}-1}{8\left(1-v_{m}\right)}$, & $S_{1212}=S_{3131}=\frac{1}{2}$, \\
tensor & $S_{3311}=S_{1122}=\frac{v_{m}}{2\left(1-v_{m}\right)}$, & $S_{3311}=S_{1122}=\frac{v_{m}}{1-v_{m}}$, \\
elements & $S_{1212}=S_{3131}=\frac{1}{4}, S_{2323}=\frac{3-4 v_{m}}{8\left(1-v_{m}\right)}$ & $S_{1111}=1$
\end{tabular}

where $v_{m}$ is the matrix Poisson's ratio. In this paper, direction " 1 " is the out of plane direction perpendicular to the circular cross section of the nanofillers. In other words, direction "1" defines the elastic modulus of the nanotubes and graphene along the axis where plane 23 is the transverse plane of isotropy. When acquiring the global stiffness matrix in the defined principal direction, the global stiffness matrix of the nanocomposites comprising the nanofillers that are oriented in other directions can also be obtained using transformation matrices. Additionally, the homogenized elastic isotropic properties of the nanocomposites containing fully random nanofillers can also be accessed. The stiffness matrix for the $r^{\text {th }}$ phase as a function of transversely isotropic stiffness matrix and Euler angles $(\theta, \phi)$ can be calculated as:

$$
C^{*}=N_{\theta}^{T} N_{\phi}^{T} C N_{\phi} N_{\theta}
$$

where $N_{\theta}$ and $N_{\phi}$ are transformation matrices. In addition, $\theta$ and $\phi$ are Euler angles. Therefore, the 
integration of the stiffness matrix for the $r^{\text {th }}$ phase in the span of $[-\pi,+\pi]$ results in the global matrix of a nanocomposite comprising reinforcements in all direction in the three dimensions. Fig. 4 shows different possible arrangement scenarios of the nanofillers within the polymeric matrix based on the design and manufacturing process. Integration of the stiffness matrix for the $r^{\text {th }}$ phase in the span of $[-\alpha,+\alpha]$ would also create a scenario like what is happening during the process of the injection molding:

$$
Q^{*}=\int_{-\pi}^{\pi} \int_{0}^{\alpha} C^{*}(\theta, \alpha) \frac{\sin \alpha}{2 \pi(1-\cos (\alpha))} d \alpha d \theta
$$

In fact, in case of thermoplastic-based nanocomposites reinforced with short fiber/nanofillers a combination of materials properties, design parameters, and manufacturing variables define the final arrangement of the fillers in the matrix. For instance in the injection molding process, design parameters such as gate position, type of gate, thickness and geometry of the component, along with other factors like viscosity of the melt, melt temperature, injection speed, etc. shape the final microstructure in the product.

Fig. 4

\section{Results and discussions}

\subsection{Nanofillers characterization}

Fig. 5 shows the derived engineering elastic constants of the carbon nanotubes from the MD simulations. The influence of the nanotube diameter on the elastic constants of the armchair $($ Chiral vector $=(n, n))$ Single Walled Carbon NanoTubes (SWCNTs) has been presented. As it can be readily seen, the longitudinal elastic and shear moduli are plunging sharply in small diameters $(<2 \mathrm{~nm})$. Moreover, while the longitudinal Poisson's ratio was nearly constant $\left(v_{12}\right.$ is decreasing from 0.17 to 0.166$)$, the transverse Poisson's ratio $\left(v_{23}\right)$ increased sharply to 0.9. This high Poisson's ratio means larger nanotubes tend to retain their circular shapes under transverse loading. Moreover, a slight variation is observed in the elastic constants after the initial sharp changes $(>3 \mathrm{~nm})$. Therefore, a nearly similar behavior can be expected from the nanotubes with larger diameters. It is also noteworthy to mention that longitudinal shear moduli $\left(\mathrm{G}_{23}\right)$ are at least 3 orders of magnitude smaller than the other achieved moduli, and are considered $1 \mathrm{MPa}$ in the microscale models.

Fig. 5 
However, most of the industrially produced CNTs or GNPs are multi-walled or multilayered. The influence of the number of walls and layers on the elastic constants of the multiwalled carbon nanotubes and multi layered GNPs are illustrated in Fig. 6 (a) and (b), respectively. The results show that the elastic constants of multiwalled carbon nanotubes increase consistently with the number of walls in their structures. The major Poisson's ratio also decreased from 0.166 in $(75,75)$ SWNT to 0.143 in 12-walled carbon nanotubes. The simulations on graphenes showed insignificant dependency to load direction. Similar behavior has also been observed in other studies, where both zigzag and armchair loading directions lead to similar values [39]. The transverse elastic moduli increased sharply with four layers, and then remained relatively constant. While longitudinal shear moduli are minuscule, the transverse shear moduli decreased from 320 to $280 \mathrm{GPa}$ with the addition of layers. Moreover, the in-plane Poisson's ratios decreased to 0.178 in 12-layererd graphenes, which is close to Poisson's ratio in graphite. It is also interesting to note that in higher number of layers, the variation rates decrease, and nearly constant values can be expected.

Despite of the acquired values for the multi layered nanofillers, it should be noted that in nanocomposites the stress is transferred via the interface between polymer and nanofillers. In other words, only the outermost layer is subjected to the applied loads. It has been shown that in the nanocomposites, the outermost layer caries most of the exerted load $[40,41]$. Therefore, the behavior of the outermost layer is defining the delivered stiffness of the fillers within the nanocomposite structure.

Fig. 6

In order to make the computational and analytical results comparable with experimental results, the incorporated nanofillers in the produced nanocomposites were characterized using TEM studies to attain their characteristics. Fig. 7 shows the SEM and TEM images of the used MWCNTs and GNPs in the nanocomposite structure. Following the performed statistical studies, multi-walled carbon nanotubes were considered with the length of $800 \mathrm{~nm}$, and outer diameter of $10.2 \mathrm{~nm}$ and 11 walls (chiral vector of $(75,75)$ ). Moreover, the average thickness of the graphene nanoplatelets was considered as $8.2 \mathrm{~nm}$, and the average area of the graphene was evaluated as $0.31 \mu \mathrm{m}^{2}$. Penny shape fillers with the diameter of $300 \mathrm{~nm}$ were included in the FEM models. 
Fig. 7

\subsection{Influence of morphology and content}

The influence of nanofillers direction and arrangement on the elastic properties of the nanocomposites was investigated using analytical and FE models. Fig. 8 shows the Mori-Tanaka modeling prediction considering the influence of level of randomness and nanofillers content on the elastic longitudinal moduli of the nanocomposites. As it can be noticed, while the values increase when adding nanofillers in the polymeric system, the elastic modulus values are decreasing drastically in more random arrangements. Close to the fully random microstructure, stiffness values end up in a nearly flat plateau. In fact, controlling the orientation of the nanofillers during the production of the nanocomposites has been challenging due to their high aspect ratios (very low bending stiffness in case of CNTs) and interfacial energy. The results show that in order to benefit from the high stiffness of the nanofillers, a moderate level of alignment is not sufficient, at least 40 percent of inclusions should be in-line with the loading direction.

\section{Fig. 8}

In order to evaluate the performance of the conducted micromechanical modeling, similar finite element based RVEs were constructed (see Fig 3(a), (b), (d), and (e)). Similar to Mori-Tanaka theory, the incorporated nanotubes in these FE models are straight cylinders. Table 1 shows the stiffness values acquired from the two models in addition to experimental results for different contents of the nanofillers. For CNT inclusions, the prediction of FE and Mori-Tanaka for elastic moduli of nanocomposites containing fully aligned nanotubes follow the same trend of sharp enhancement. While the analytical predictions are consistently higher than FE results, the results differ $20 \%$ in 5 wt. \% inclusion. However, the predictions for random scenarios are nearly the same, and less than $2 \%$ difference can be noticed. However, the modeling predictions were significantly higher than the experimental results. Moreover, despite the trend of experimental values, the elastic moduli increased linearly.

Contrary to the CNT inclusions, the prediction based on the two models for the nanocomposites containing GNPs are notably different. The Mori-Tanaka results are always larger than the ones from FE modeling. However, the FE simulation results are smaller and close to the experimental values. It is also interesting to note that the results for elastic modulus for aligned and randomly oriented structures are close especially 
compared to the cylindrical reinforcement. This behavior can be attributed to the two-dimensional geometry of the penny shape inclusions compared to one-dimensional reinforcement of rod-shape nanofillers. Furthermore, it is noteworthy to mention that as the content of the nanofillers increases in the composite systems, the deviation between the modeling predictions increases. This behavior is due to the fact that in higher contents of the nanofillers, some of the made assumptions in the micromechanical modeling might not be viable anymore. In the Mori-Tanaka scheme, it is assumed that the interactions of the nanofillers and the corresponding stress fields lead to homogenous strain fields in the fillers. However, as the content of the nanofillers in the composites increases, the reduced distance between the nanofillers lead to increased interactions between adjacent stress fields. Therefore, the resulting non-homogenous strain fields in the FE models and experiments leads to deviation of the results of the different methods in higher contents of the nanofillers.

Table 1

In order to make the finite element models more realistic and more closely represent to the actual microstructure of the nanocomposites, random curvatures were added to the fibers. Regardless of the curvature, the defined coordinate systems along the spine of the fibers guarantee the acquired transversely isotropic properties on all cross sections of the fibers. Fig 9 shows the a comparison between the electron microscopy images acquired from the cross section of produced nano and hybrid composites with the modified RVE models.

Fig. 9

Moreover, after optimization of the processing methods, no large agglomerate was noted in the microstructure of the nanocomposite reinforced with MWCNTs. In fact, one or two agglomerates with the diameter of less than $4 \mu \mathrm{m}$ in the area of $400 \mu \mathrm{m}^{2}$ might be detected (Fig. 10(a)). However, while GNPs were not curved or bent like CNTs within the nanocomposite structures, electron microscopy investigations showed that the used manufacturing method has led to a number of agglomerates for higher contents of graphene. Fig. 10(b) shows one of these agglomerates which was usually noted in stack of several GNP layers. Therefore, in the FE models corresponding to 5.0 wt. \% GNP reinforced nanocomposites, $30 \%$ of the GNPs were stacked into 
groups of four to investigate this effect.

Fig. 10

Fig. 11 compares the modified RVE FE simulation results with the initial FE modeling and experimental results. As it can be seen, the modified RVE FE results are much closer to the experimental values in all contents. In fact, both experimental and FE modeling results follow a similar trend (Fig. 11(a)). This pattern is interesting since the observed reduction of enhancement rate in experiments is commonly attributed to the presence of agglomerations [42-44]. However while no agglomeration was included in the modeling, the decrease in the rate of enhancement was still observed. While, including random straight fillers led to linear enhancement with the addition of nanofillers in the composites, the implemented mimicked structure from the produced composites resulted into similar trend to experimental values.

A major difference between FE modeling and experimental results in the GNP reinforced composites were observed for higher contents. Inclusion of the $30 \%$ agglomeration in the structure of the composites based on the electron microscopy investigations compensated for this difference with $10 \%$ reduction of the model prediction. Moreover, if numerical and experimental statistical deviations are not considered, it seems that experimental values are higher than the modeling results especially for lower contents. This can be attributed to the characteristics of the production method of the nanocomposites in this study. In the injection molding process high shear forces are applied on the nanocomposite melts. Therefore, increased orientation among fillers is expected in lower contents where high interfacial attraction forces are lower. In fact, Van der Waals forces reduce as the average distance between the nanofillers increases (compare Figs. 7(c) and 9(b)) [45].

Fig. 11

Fig. 12 shows a comparison between the FE modeling and experimental results in hybrid nanocomposites containing both CNTs and GNPs. As it can be noticed, the experimental and modeling results are quite close. In addition, they follow a similar trend with the lowest elastic modulus in CNT inclusions and increasing with the addition of GNPs. However, the produced nanocomposite containing $2.0 \mathrm{wt}$ \% CNT and $1.0 \mathrm{wt}$ \% GNP is an exception. This synergic behavior has been observed in some other studies [46]. The protection of the nanofillers against processing damages and improved dispersion have been attributed to this phenomenon. 
Fig. 12

\section{Conclusions}

Multiscale modeling inspired from the microstructure of the nanocomposites was performed. In this study, the elastic behavior of the nanocomposites reinforced with two types of nanofillers were studied using analytical, computational, and experimental tools. Nano and hybrid composites containing carbon nanotubes and graphene fillers with the contents up to $5.0 \mathrm{wt} . \%$ were prepared and characterized. The influence of nanofiller characteristics such as number of layers and nanotubes diameters on the stiffness matrices were studied using molecular dynamics simulations. The results showed that after a certain diameter or number of layers, nearly constant values can be considered for the stiffness parameters of nanofillers. The structure and morphology of the produced nanocomposites were also studied in nano and micro scales. Subsequently, the derived transversely isotropic matrices with the actual characteristics acquired from electron microscopy were included in micromechanical Mori-Tanaka and FE models. Regardless of morphology, Mori-Tanaka and FE models containing random straight fillers tended to overestimate the elastic values. However, proper introduction of transverse isotropy to fibers and morphologies similar to the produced samples largely eliminated the differences. Considering fully random curved nanofillers reduced the difference between modeling and experimental results to less than $4 \%$. In addition, the reduction of the enhancement slope for higher nanofiller contents was attained in FE results. Unlike previous studies, this trend indicates that the reduction of enhancement rate is not just a collateral influence of agglomerations in the nanocomposite structures. In fact, in a random microstructure, which is delivered by most of the conventional processing methods, the stress distribution arising from the smaller average distances between the fillers leads to reduced enhancement for higher filler contents. The conducted realistic modeling considering actual nanofiller characteristics and nanocomposite morphologies showed that the observed behavior of the nanocomposites can be predicted with a fair level of confidence.

\section{References}

[1] Alishahi E, Shadlou S, Doagou-R S, Ayatollahi MR. Effects of Carbon Nanoreinforcements of 
Different Shapes on the Mechanical Properties of Epoxy-Based Nanocomposites. Macromol Mater Eng 2013;298:670-8. doi:10.1002/mame.201200123.

[2] Doagou-Rad S, Islam A, Jensen JS. Influence of Processing Conditions on the Mechanical Behavior of MWCNT Reinforced Thermoplastic Nanocomposites. Procedia CIRP 2017;66:131-6. doi:10.1016/j.procir.2017.03.362.

[3] Aragh BS, Barati AHN, Hedayati H. Eshelby-Mori-Tanaka approach for vibrational behavior of continuously graded carbon nanotube-reinforced cylindrical panels. Compos Part B Eng 2012;43:1943-54.

[4] Mortazavi B, Baniassadi M, Bardon J, Ahzi S. Modeling of two-phase random composite materials by finite element, Mori-Tanaka and strong contrast methods. Compos Part B Eng 2013;45:1117-25. doi:https://doi.org/10.1016/j.compositesb.2012.05.015.

[5] Zhou X, Shin E, Wang KW, Bakis CE. Interfacial damping characteristics of carbon nanotube-based composites. Compos Sci Technol 2004;64:2425-37.

[6] Ayatollahi MR, Doagou-Rad S, Shadlou S. Nano-/microscale investigation of tribological and mechanical properties of epoxy/MWNT nanocomposites. Macromol Mater Eng 2012;297:689-701. doi:10.1002/mame.201100271.

[7] Zeng QH, Yu AB, Lu GQ. Multiscale modeling and simulation of polymer nanocomposites. Prog Polym Sci 2008;33:191-269.

[8] Thostenson ET, Chou T-W. On the elastic properties of carbon nanotube-based composites: modelling and characterization. J Phys D Appl Phys 2003;36:573.

[9] Thostenson E, Li C, Chou T. Nanocomposites in context. Compos Sci Technol 2005;65:491-516. doi:10.1016/j.compscitech.2004.11.003.

[10] Peng B, Locascio M, Zapol P, Li S, Mielke SL, Schatz GC, et al. Measurements of near-ultimate strength for multiwalled carbon nanotubes and irradiation-induced crosslinking improvements. Nat Nanotechnol 2008;3:626-31.

[11] Ding W, Calabri L, Kohlhaas KM, Chen X, Dikin DA, Ruoff RS. Modulus, fracture strength, and brittle vs. plastic response of the outer shell of arc-grown multi-walled carbon nanotubes. Exp Mech 
$2007 ; 47: 25-36$.

[12] Odegard GM, Gates TS, Wise KE, Park C, Siochi EJ. Constitutive modeling of nanotube-reinforced polymer composites. Compos Sci Technol 2003;63:1671-87. doi:https://doi.org/10.1016/S02663538(03)00063-0.

[13] Alian AR, Kundalwal SI, Meguid SA. Multiscale modeling of carbon nanotube epoxy composites. Polymer (Guildf) 2015;70:149-60. doi:10.1016/j.polymer.2015.06.004.

[14] Fisher FT, Bradshaw RD, Brinson LC. Fiber waviness in nanotube-reinforced polymer compositesI: Modulus predictions using effective nanotube properties. Compos Sci Technol 2003;63:1689-703.

[15] Bradshaw RD, Fisher FT, Brinson LC. Fiber waviness in nanotube-reinforced polymer compositesII: modeling via numerical approximation of the dilute strain concentration tensor. Compos Sci Technol 2003;63:1705-22.

[16] Fertig RS, Garnich MR. Influence of constituent properties and microstructural parameters on the tensile modulus of a polymer/clay nanocomposite. Compos Sci Technol 2004;64:2577-88. doi:https://doi.org/10.1016/j.compscitech.2004.06.002.

[17] Ayatollahi MR, Shadlou S, Shokrieh MM. Multiscale modeling for mechanical properties of carbon nanotube reinforced nanocomposites subjected to different types of loading. Compos Struct 2011;93:2250-9. doi:https://doi.org/10.1016/j.compstruct.2011.03.013.

[18] Tsai J-L, Tzeng S-H, Chiu Y-T. Characterizing elastic properties of carbon nanotubes/polyimide nanocomposites using multi-scale simulation. Compos Part B Eng 2010;41:106-15. doi:https://doi.org/10.1016/j.compositesb.2009.06.003.

[19] Choi HJ, Kim SG, Hyun YH, Jhon MS. Preparation and Rheological Characteristics of Solvent-Cast Poly(ethylene oxide)/Montmorillonite Nanocomposites. Macromol Rapid Commun 2001;22:320-5. doi:10.1002/1521-3927(20010301)22:5<320::AID-MARC320>3.0.CO;2-3.

[20] Choi J, Shin H, Yang S, Cho M. The influence of nanoparticle size on the mechanical properties of polymer nanocomposites and the associated interphase region: A multiscale approach. Compos Struct 2015;119:365-76. doi:https://doi.org/10.1016/j.compstruct.2014.09.014.

[21] Chanteli A, Tserpes KI. Finite element modeling of carbon nanotube agglomerates in polymers. 
Compos Struct 2015;132:1141-8. doi:https://doi.org/10.1016/j.compstruct.2015.07.033.

[22] Mishnaevsky L. Nanostructured interfaces for enhancing mechanical properties of composites: Computational micromechanical studies. Compos Part B Eng 2015;68:75-84.

doi:https://doi.org/10.1016/j.compositesb.2014.08.029.

[23] Doagou-Rad S, Islam A, Jensen JS. Correlation of mechanical and electrical properties with processing variables in MWCNT reinforced thermoplastic nanocomposites. J Compos Mater 2018;52:3681-3697. doi:10.1177/0021998318768390.

[24] Doagou-Rad S, Islam A, Jensen JS, Alnasser A. Interaction of nanofillers in injection-molded graphene/carbon nanotube reinforced PA66 hybrid nanocomposites. J Polym Eng 2018;0. doi:10.1515/polyeng-2018-0060.

[25] Plimpton S. Fast parallel algorithms for short-range molecular dynamics. J Comput Phys 1995;117:119.

[26] Stuart SJ, Tutein AB, Harrison JA. A reactive potential for hydrocarbons with intermolecular interactions. J Chem Phys 2000;112:6472-86.

[27] Brenner DW, Shenderova OA, Harrison JA, Stuart SJ, Ni B, Sinnott SB. A second-generation reactive empirical bond order (REBO) potential energy expression for hydrocarbons. J Phys Condens Matter 2002;14:783.

[28] Nosé S. A molecular dynamics method for simulations in the canonical ensemble. Mol Phys $1984 ; 52: 255-68$.

[29] Pontefisso A, Mishnaevsky L. Nanomorphology of graphene and CNT reinforced polymer and its effect on damage: Micromechanical numerical study. Compos Part B Eng 2016;96:338-49.

[30] Mishnaevsky L, Dai G. Hybrid and hierarchical nanoreinforced polymer composites: Computational modelling of structure-properties relationships. Compos Struct 2014;117:156-68. doi:https://doi.org/10.1016/j.compstruct.2014.06.027.

[31] Dai G, Mishnaevsky L. Fatigue of multiscale composites with secondary nanoplatelet reinforcement: 3D computational analysis. Compos Sci Technol 2014;91:71-81. doi:https://doi.org/10.1016/j.compscitech.2013.11.024. 
[32] Mishnaevsky L, Dai G. Hybrid carbon/glass fiber composites: Micromechanical analysis of structuredamage resistance relationships. Comput Mater Sci 2014;81:630-40. doi:https://doi.org/10.1016/j.commatsci.2013.08.024.

[33] Pontefisso A, Zappalorto M, Quaresimin M. Effectiveness of the random sequential absorption algorithm in the analysis of volume elements with nanoplatelets. Comput Mater Sci 2016;117:511-7. doi:https://doi.org/10.1016/j.commatsci.2016.02.024.

[34] Hibbit HD, Karlsson BI, Sorensen EP. ABAQUS user manual, version 6.12. Simulia, Provid RI 2012.

[35] Mori T, Tanaka K. Average stress in matrix and average elastic energy of materials with misfitting inclusions. Acta Metall 1973;21:571-4.

[36] Eshelby JD. The determination of the elastic field of an ellipsoidal inclusion, and related problems. Proc. R. Soc. London A Math. Phys. Eng. Sci., vol. 241, The Royal Society; 1957, p. 376-96.

[37] Benveniste Y. A new approach to the application of Mori-Tanaka's theory in composite materials. Mech Mater 1987;6:147-57.

[38] Mura T. Micromechanics of defects in solids. Martinus Nijhoff Publishers; 1982.

[39] Gamboa A, Vignoles GL, Leyssale J-M. On the prediction of graphene's elastic properties with reactive empirical bond order potentials. Carbon N Y 2015;89:176-87. doi:https://doi.org/10.1016/j.carbon.2015.03.035.

[40] Lau K-T, Gu C, Gao G-H, Ling H, Reid SR. Stretching process of single-and multi-walled carbon nanotubes for nanocomposite applications. Carbon N Y 2004;42:426-8.

[41] Wei C, Cho K, Srivastava D. Tensile yielding of multiwall carbon nanotubes. Appl Phys Lett 2003;82:2512-4. doi:10.1063/1.1567041.

[42] Hammerand DC, Seidel GD, Lagoudas DC. Computational micromechanics of clustering and interphase effects in carbon nanotube composites. Mech Adv Mater Struct 2007;14:277-94.

[43] Shi D-L, Feng X-Q, Huang YY, Hwang K-C, Gao H. The effect of nanotube waviness and agglomeration on the elastic property of carbon nanotube-reinforced composites. J Eng Mater Technol 2004;126:250-7.

[44] Montazeri A, Javadpour J, Khavandi A, Tcharkhtchi A, Mohajeri A. Mechanical properties of multi- 
walled carbon nanotube/epoxy composites. Mater Des 2010;31:4202-8. doi:https://doi.org/10.1016/j.matdes.2010.04.018.

[45] Hamaker HC. The London — van der Waals attraction between spherical particles. Physica 1937;4:1058-72. doi:10.1016/S0031-8914(37)80203-7.

[46] Zhang S, Yin S, Rong C, Huo P, Jiang Z, Wang G. Synergistic effects of functionalized graphene and functionalized multi-walled carbon nanotubes on the electrical and mechanical properties of poly (ether sulfone) composites. Eur Polym J 2013;49:3125-34. 


\section{Figure Captions:}

Fig. 1 Constructed atomistic multi layered (a) carbon nanotubes, and (b) graphene for molecular dynamics simulations.

Fig. (2) (a) and (b) Constructed nanocomposites FE representative volume element including snake shape nanofillers. Assigning transversely isotropic properties to (c) carbon nanotubes and (d) graphene within the RVEs.

Fig. 3 Constructed RVE models: (a) aligned straight CNTs, (b) random straight CNTs, (c) random curved CNTs, (d) aligned GNPs, (e) random GNPs, and (f) hybrid CNT/GNP composites.

Fig. 4 Schematic of the nano-reinforcements arrangements in the nanocomposite: (a) aligned in the direction of loading, (b) aligned but not in the direction of loading, (c) some level of alignment, and (d) fully random. Fig. 5 Influence of nanotube diameter on the elastic constants of armchair SWCNTs.

Fig. 6 Influence of (a) number of nanotubes walls and (b) number of graphene layers on their elastic constants. The MWCNTs are ending up to an armchair nanotube with chiral vector of $(75,75)$ as the outermost tube.

Fig. 7 TEM micrographs of the used nanofillers representing (a) cross section multiwalled carbon nanotubes, and (b) cross-section of multi-layer graphenes, (c) length of MWCNTs, and (d) area of GNPs.

Fig. 8 Influence of content and randomness level on the longitudinal elastic modulus of the nanocomposites.

Fig. 9 SEM, TEM, and FE images of composites reinforced with (a)-(c) carbon nanotubes, and (d)-(f) and both CNTs and GNPs.

Fig. 10 (a) Dispersion in CNT reinforced composites, and (b) stack of graphene layers in GNP reinforced composites. 
Fig. 11 Comparison between FE modeling and experimental results for (a) MWCNT and (b) GNP reinforcements.

Fig. 12 comparison between FE modeling and experimental results in hybrid nanocomposites.

Table 1. Comparison of finite element and analytical modeling with experimental results

\begin{tabular}{|c|c|c|c|c|c|c|}
\hline \multirow{2}{*}{ Nanofiller type } & \multirow{2}{*}{ Wt. (\%) } & \multicolumn{2}{|c|}{ FEM } & \multicolumn{2}{|c|}{ Mori-Tanaka } & \multirow[t]{2}{*}{ Experiments } \\
\hline & & Aligned & Random & Aligned & Random & \\
\hline \multirow{4}{*}{$\mathrm{CNT}$} & 0.5 & 4.04 & 3.15 & 4.42 & 3.04 & 3.0 \\
\hline & 1.0 & 4.95 & 3.45 & 6.10 & 3.34 & 3.2 \\
\hline & 3.0 & 10.24 & 4.61 & 12.8 & 4.52 & 3.5 \\
\hline & 5.0 & 15.83 & 5.79 & 19.5 & 5.71 & 3.75 \\
\hline \multirow{4}{*}{ GNP } & 0.5 & 3.03 & 2.98 & 4.69 & 3.71 & 3.15 \\
\hline & 1.0 & 3.28 & 3.09 & 6.63 & 4.71 & 3.4 \\
\hline & 3.0 & 4.23 & 3.62 & 13.94 & 8.34 & 3.7 \\
\hline & 5.0 & 4.97 & 4.42 & 21.4 & 12.10 & 3.86 \\
\hline
\end{tabular}


(a)

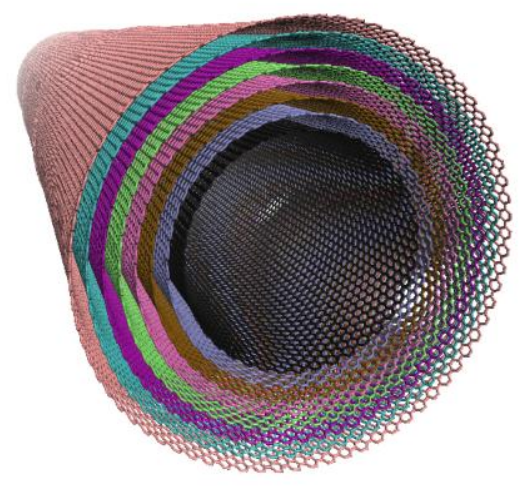

(b)

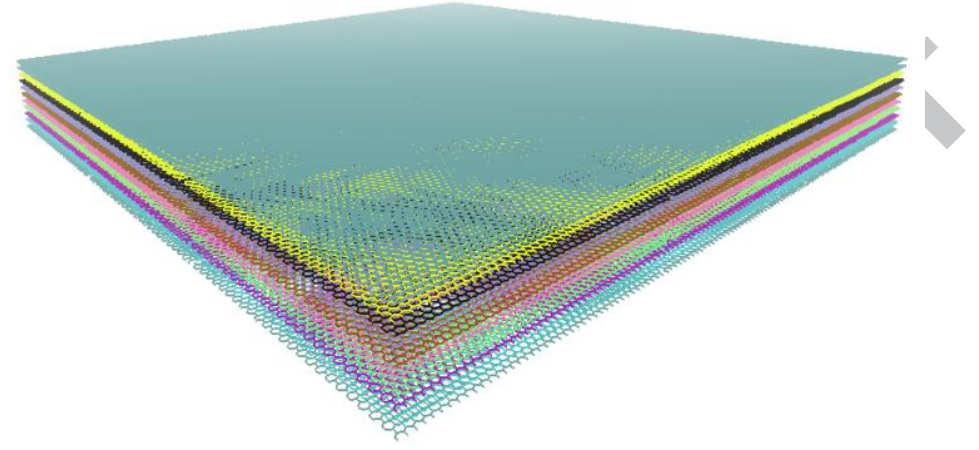

5 


\section{ACCEPTED MANUSCRIPT}

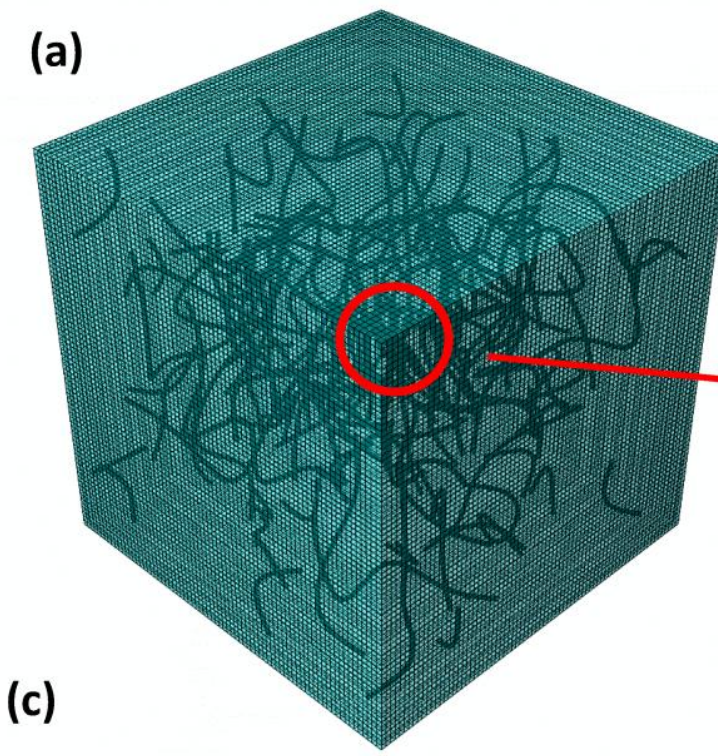

(b)
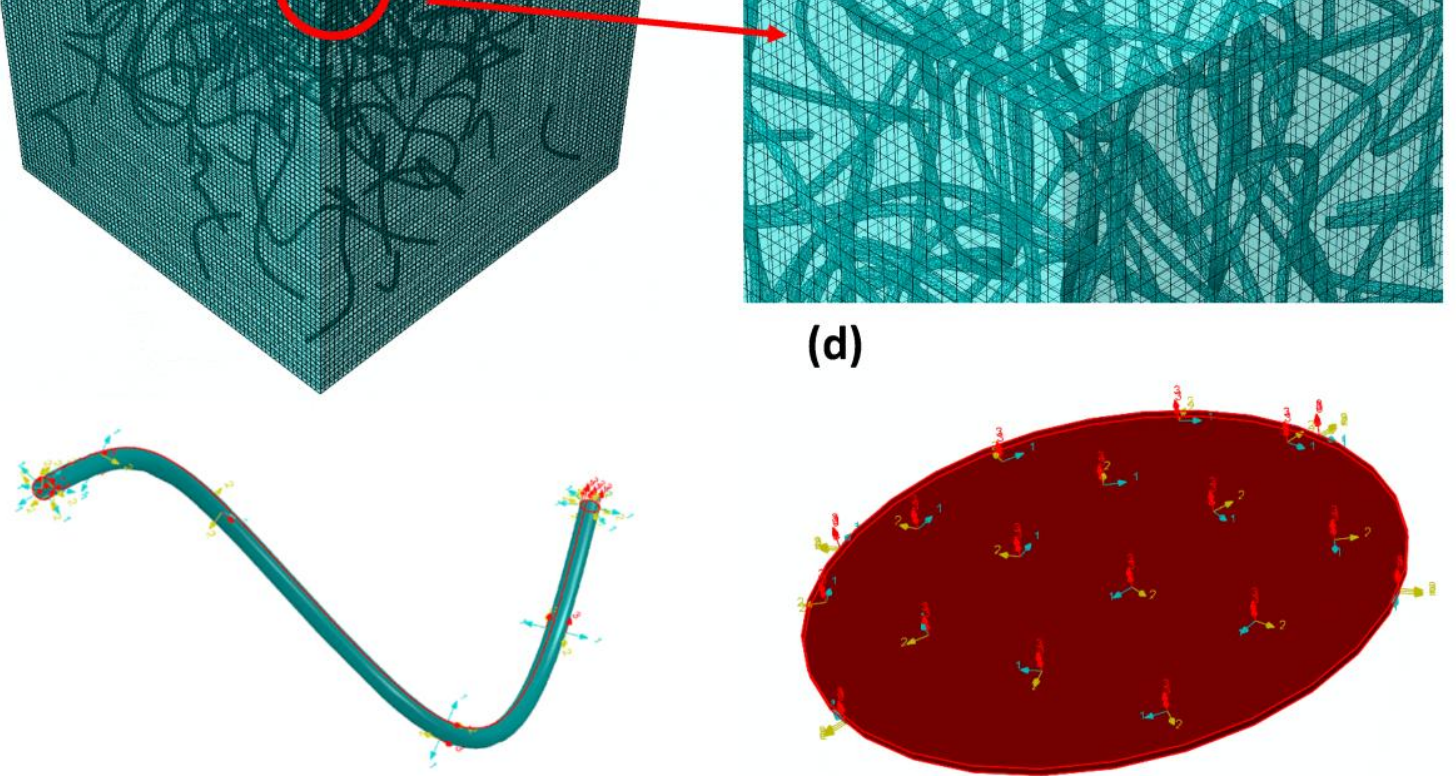

(d)

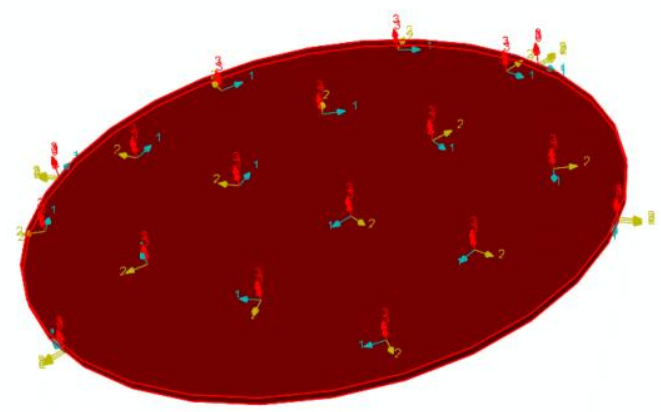




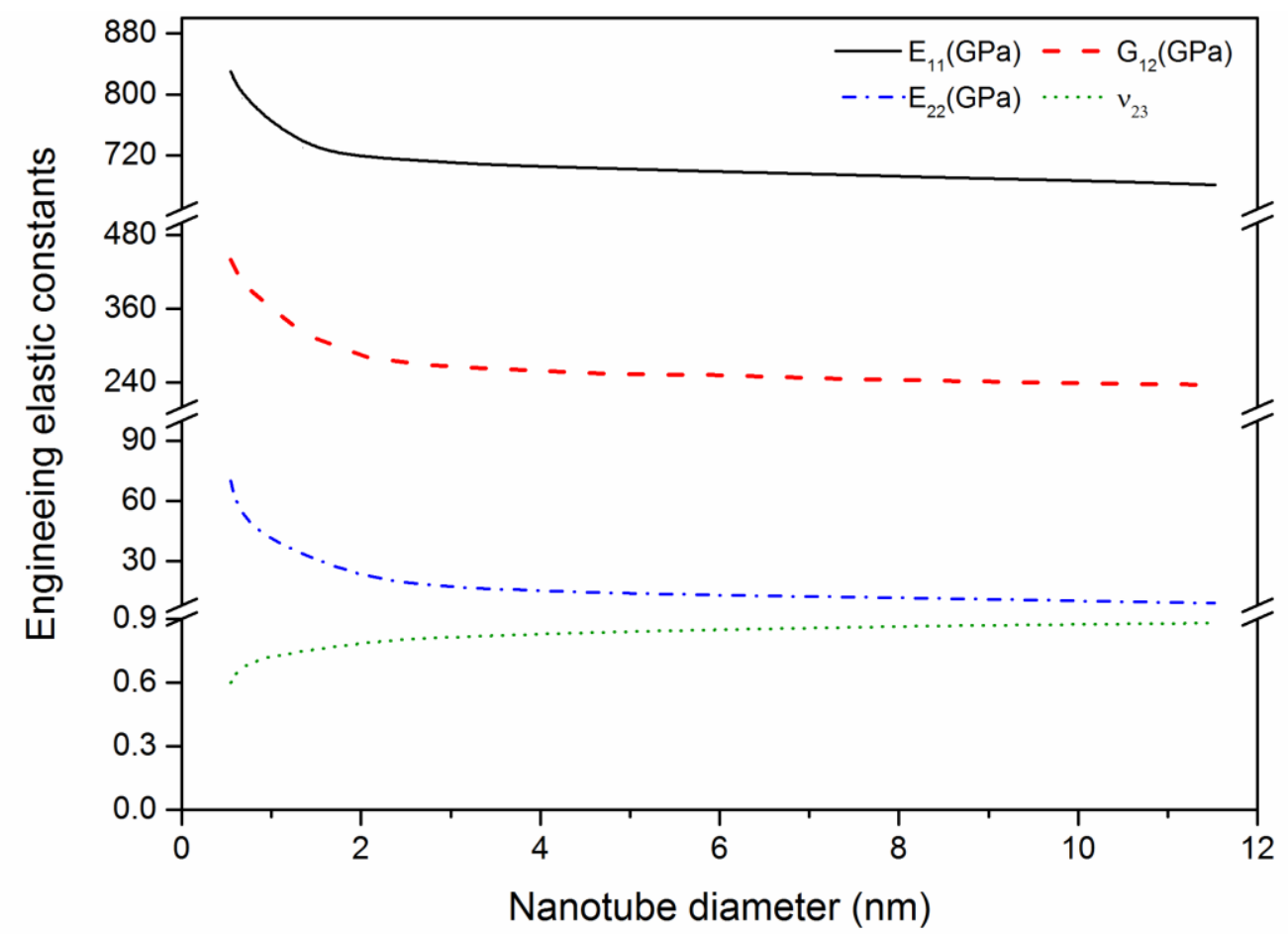


(a)

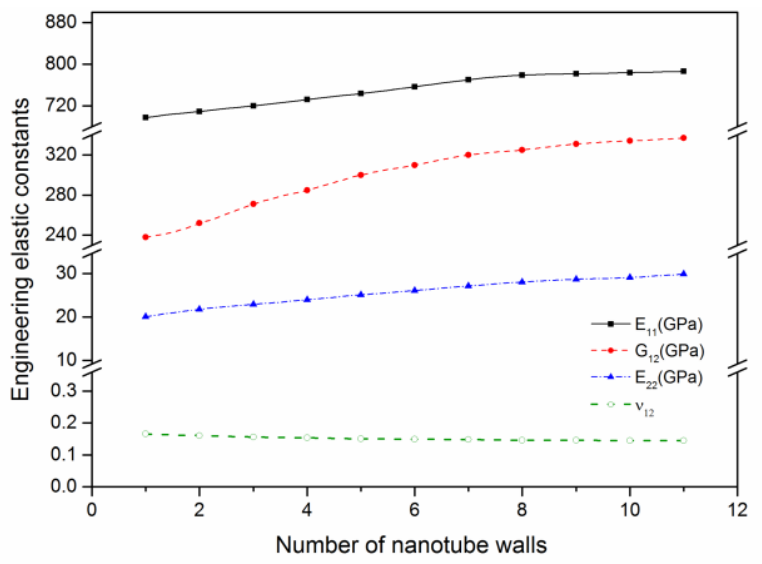

(b)

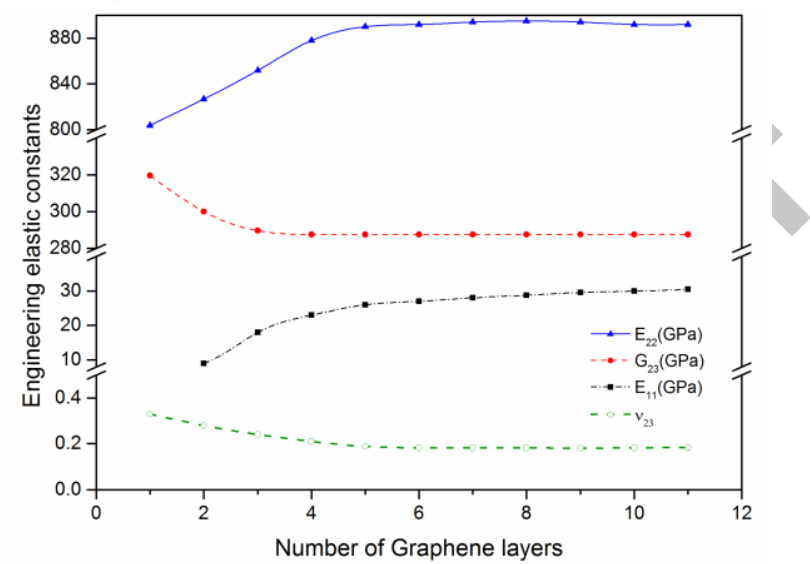



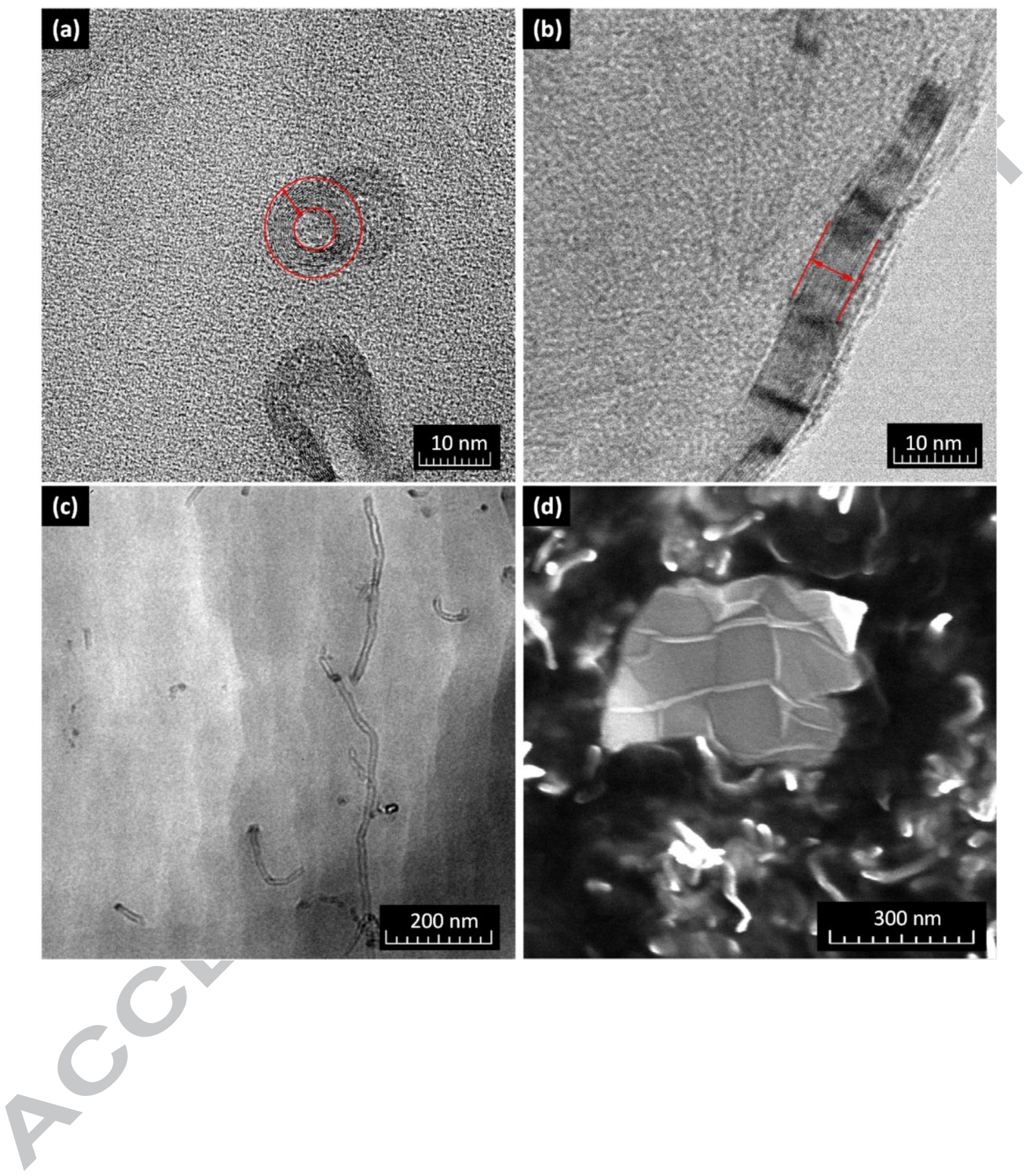
(a)

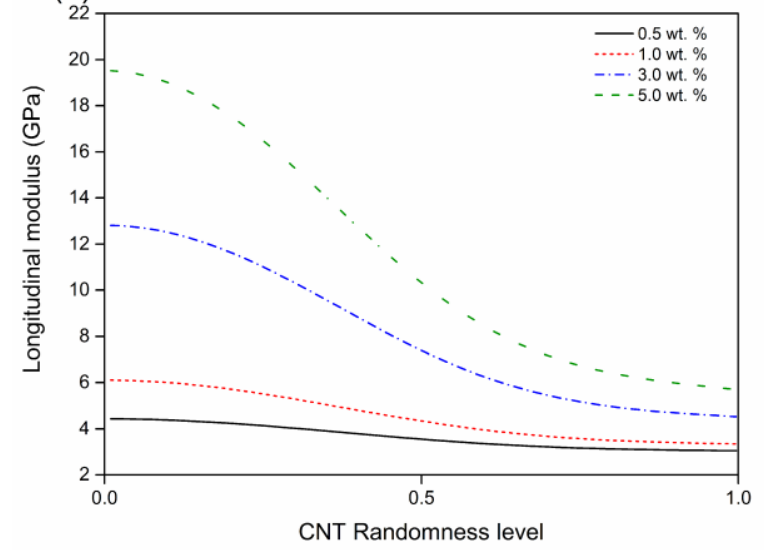

(b)

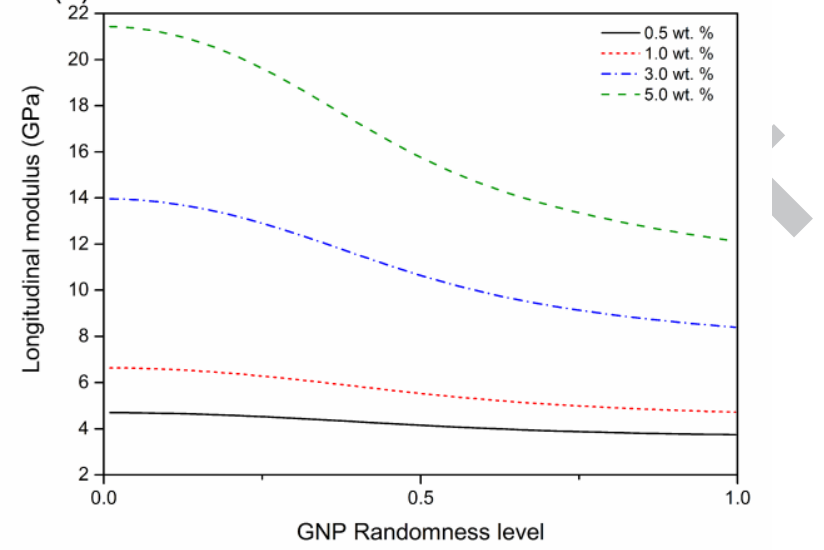



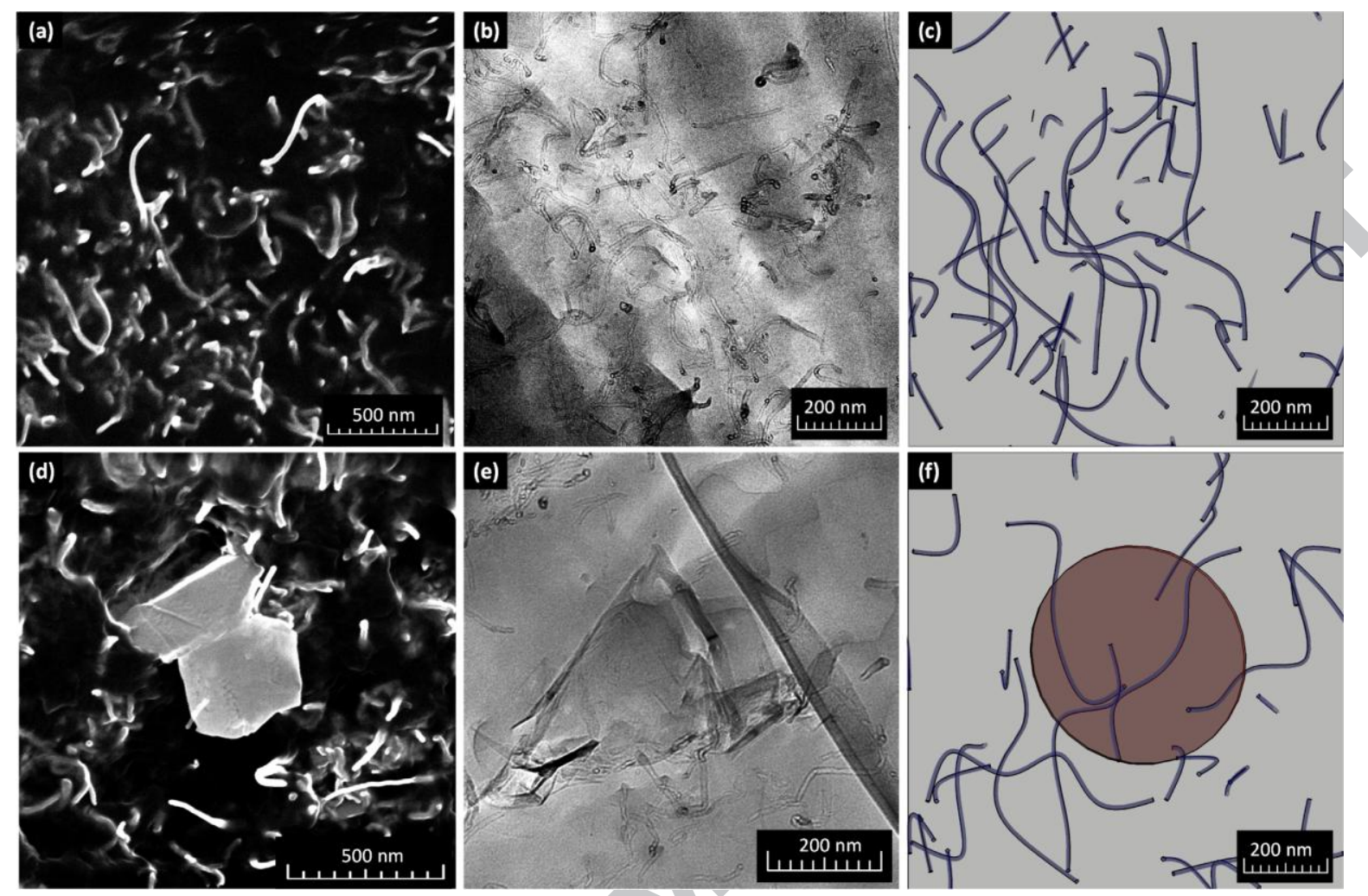

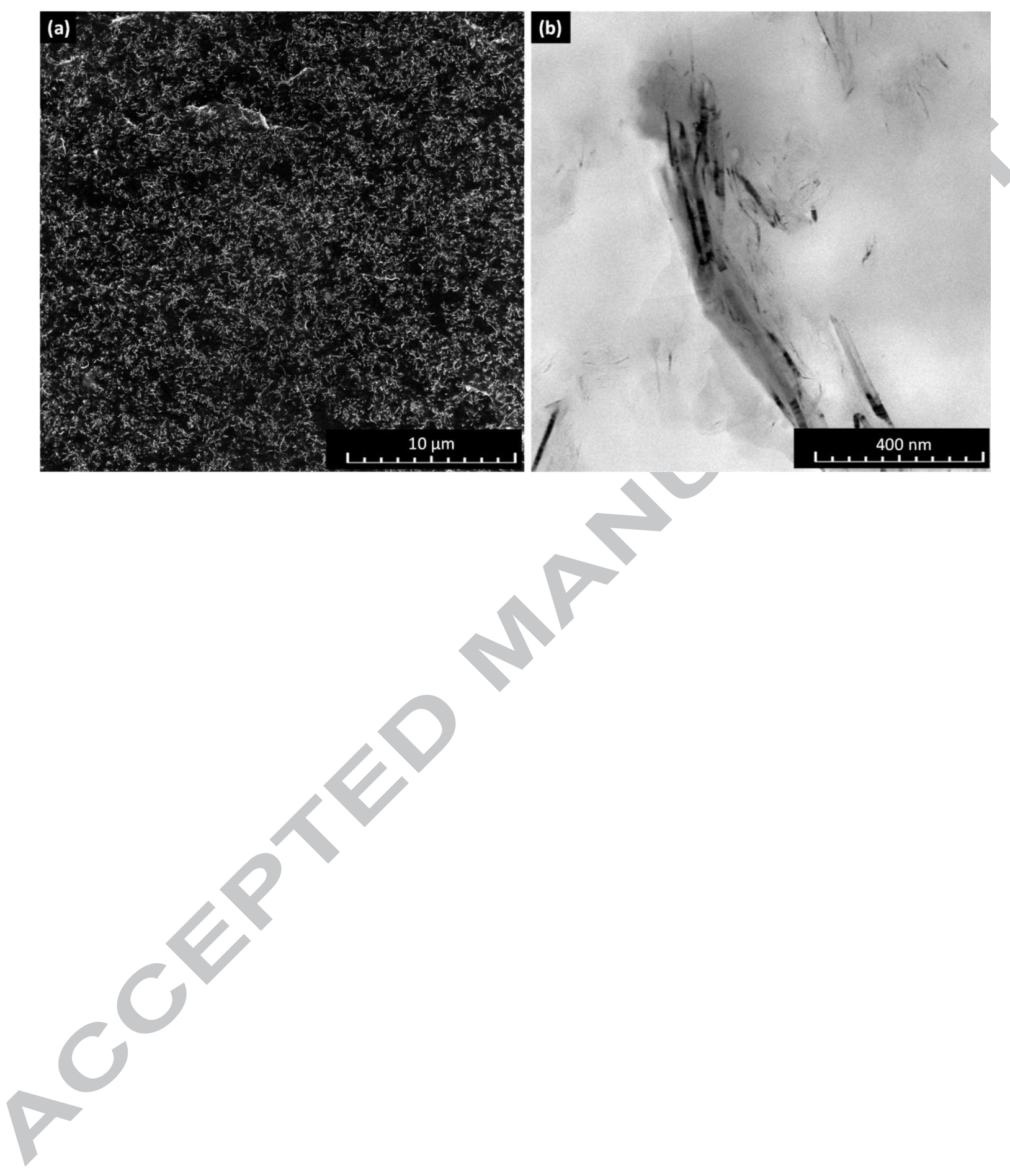


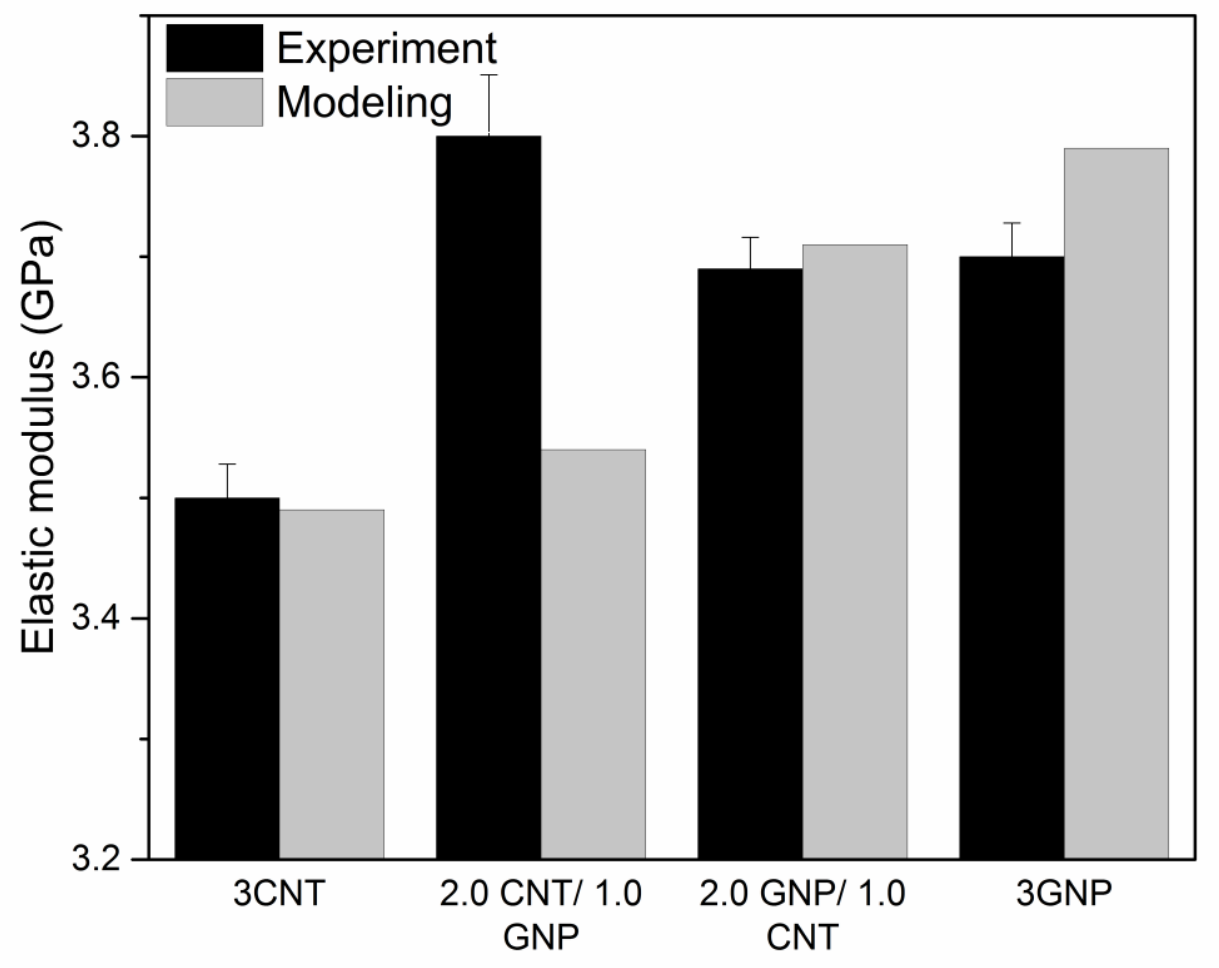

Nanocomposite content (wt. \%) 